\title{
Hybrid GWO and CS Algorithm for UPQC Positioning in the Power Distribution Network
}

\author{
Yongsheng Xu \\ University of Central Florida, Orlando, FL 32816, United States \\ yongshengxu123@gmail.com
}

\begin{abstract}
Currently, Flexible Alternating Current Transmission System (FACTS) devices, particularly UPQC are established to encompass important impacts on rising power system stability. Numerous intellectual optimization algorithms were used to positioning the Unified Power Quality Conditioner (UPQC) in the power systems. Nevertheless, those optimization algorithms did not succeed to present more reliability and the feedback signal. Therefore, this work proposes a Power Quality enhancement technique that is based on a hybrid approach that connects Grey Wolf Optimization (GWO) and Cuckoo Search Algorithm (CSA). Also, the developed technique discovers the optimal position of UPQC device which focuses on the cost of UPQC, Voltage Stability Index (VSI) and power losses. The developed technique is performed in IEEE 33 and 69, test bus systems. Moreover, developed technique performance is illustrious over other exiting techniques namely GWO, Whale Optimization Algorithm (WOA), Artificial Bee Colony (ABC), Worst Solution linked WOA update (WS WU), WS-WU, Genetic Algorithm (GA), Dragonfly (DA) and Firefly (FF). The developed technique performance is efficiently shown by its performance and convergence analysis.
\end{abstract}

Keywords: UPQC; Power Loss; Power Quality; VSI; Optimization Algorithm

\begin{tabular}{ll} 
Nomenclature \\
\hline Abbreviations & Descriptions \\
\hline FACTS & Flexible Alternating Current Transmission System \\
SCIG & Squirrel Cage Induction Generator \\
UPQC & Unified Power Quality Conditioner \\
ABC & Artificial Bee Colony \\
APFs & Active Power Filters \\
CSA & Cuckoo Search Algorithm \\
PQ & Power Quality \\
PEMFC & Proton Exchange Membrane Fuel Cell \\
PAC & Power Angle Control \\
GWO & Grey Wolf Optimization \\
SC & Super Capacitor \\
VA & Volt-Ampere \\
WS-WU & Worst Solution Linked Whale Optimization Algorithm Update \\
VSI & Voltage stability Index \\
FF & Firefly \\
CS & Cuckoo search \\
DS & Distribution System \\
VA & Volt Amperes \\
MGWO & Modified Grey Wolf Optimization \\
DG & Distributed Generation \\
OBL & Opposition-based learning \\
PV & Photovoltaic \\
SAPF & Shunt active power filter \\
\hline
\end{tabular}




\section{Introduction}

The chief challenges of the smart grid are power quality. Power quality problems like harmonic distortions have been rising quickly due to the rise in the exploitation of power electronic converters [1]. For PQ problems, APFs being rapid, and dynamic, are favored over passive filters to recompense. Series Active Power Filter principally compensates to supply voltage associated PQ concerns namely voltage swell, sag, and harmonics. Conversely, Shunt Active Power Filter primarily compensates for load current associated PQ concerns like unbalance, deprived power factor, and harmonics. UPQC is the incorporation of the shunt and series Active Power Filter distributes a widespread DC link [19]. UPQC, incorporating advantages of both shunt and series Active Power Filter, compensates for the majority of PQ problems $[20]$.

UPQC represents a multitasking power conditioner that can exploit compensation a lot of voltage disturbances of voltage fluctuations, power supply, and to avert harmonic load current from the incoming power system. It indicates a traditional power device modeled to ease disturbances that affect the sensitive loads' performance [1]. UPQC comprises of 2 voltage-source inverters through a widespread dclink modeled in single-phase, 3-phase 3-wire, or 3 phase 4 -wire configurations. The series Active Filter compensates for voltage supply disturbances for example flickers, imbalances, harmonics, swell, sag, and negative and zero sequence components. For load current distortions the shunt filter compensates for instances occurred by imbalances, harmonics, and reactive power and carries out the voltage regulation of dc link [18].

To act for voltage swells or sag, voltage harmonics, on the series side and reactive power compensation, load unbalance compensation, current harmonic compensation, and enhancement of power factor on parallel side UPQC is exploited. Conversely, the PQ issues via electrical networks possess the increased purpose of a lot of researchers; [7] has developed the control and the topology of a UPQC which can be exploited for the improvement of PQ. Also, an enhanced fuel cell-based controller of UPQC expands its ability in PQ for dual topology was examined in [8]. In [9] a 3-phase UPQC based combination of PEMFC to alleviate voltage sag and current harmonic was described. Numerous researchers encompass worked to intelligent methods to manage these FACTS like fuzzy logic controller Performance for managing SAPF was examined [10] that is fine renowned for enhancements of both performances of the steady-state and transient. The disturbing controller is exploited as an adaptive controller that shows to encompass maximum ability control DVR through an easy model.

The main contribution of a proposed technique is used for the optimal positioning and the sizing of UPQC in power DS exploiting hybridization of GWO and CS. In developed technique, opposition based learning of GWO is persuaded in CS, and consequently, the developed technique is called as hybrid GWO-CSA. The recommended technique discovers the optimal position of UPQC device by regarding power losses, cost of UPQC, and VSI. Also, the developed technique performance is evaluated with the conventional techniques such as FF, ABC, GWO, WS-WU, WOA, GA and DA, and the developed technique is analyzed in IEEE 33 and 69 test bus systems.

\section{Literature Review}

In 2020, Ashish Patel et al [1] developed an optimum sizing algorithm for UPQC-DG based on an enhanced PAC method that shares reactive power burden among shunt and series converters. With the exception of optimal-sizing, by the integration of the VA restricts in PAC approach to assure converters operation in modeled ratings in all circumstances. In 2020, Guilherme Masquetti Pelz et al [2], developed a Distributed Generators system incorporating a Photo Voltic system using a one-Phase to three-Phase UPQC-1PH-3PH. The scheme called DG-UPQC-1PH-3PH inserts to grid the energy created from a PV array, causative to supply loads. In addition the active power injection to the grid, DG-UPQC-1PH-3PH enhances PQ indicators, like grid voltage harmonics, voltage swells/ sags, and power factor. In 2019, S.Lakshmi Kanthan Bharathi and S. Selvaperumal [3] worked on the UPQC with an MGWO based on the Proportional Integral controller incorporated through renewable energy such as Wind turbine SCIG was developed to eliminate current and voltage harmonics imperfection accurately. Similarly, MGWO was as well used in UPQC. In 2018, Ashish Patel et al [4], proposed an enhanced control approach for by means of an unbalanced load. Shunt APF was overburdened while it unaccompanied equipment total load reactive power in UPQC. PAC algorithm aspires at effectual use of shunt and series APFs by distribution reactive power burden. Conventional PAC techniques can lead to the flow of reactive power among 2 Active Power Filters and thus consequence in UPQC overloading in attendance of unbalanced load. Here, a novel PAC algorithm was developed that evades the flow of reactive power and redundant VA load on UPQC. In 2018, Brahim Berbaoui [5], developed an optimal control approach for UPQC to 
enhance $\mathrm{PQ}$ and control efficiently equal power-sharing among series and shunt UPQC inverter in electrical errors circumstance. A hybrid power generator that combines a PEMFC as a major energy source, and SC as a secondary source, was developed to provide for the FACT device. In 2016, Gowtham $\mathrm{N}$ and Dr.Shobha Shankar [6], worked on UPQC that was an integration of shunt and series APFs. The series APFs mitigates voltage based distortions when shunt active power filters alleviate current based distortion. UPQC alleviates current and voltage based distortion concomitantly and separately. UPQC enhances PQ through compensating both loads and current harmonics that thus create load voltage and source current sinusoidal at the necessary voltage level.

\section{Optimal Positioning and sizing of UPQC}

\subsection{Objective Function}

The most important characteristic following the developed PQ improvement is the UPQC position. The positioning of UPQC encompasses to fulfil objectives for getting better PQ. The objective model of the executed model is shown in eq. (1). In Eq. (4), $\mathrm{P}_{\text {Loss }}$ is stated [12] which shows the power loss. Moreover, $\mathrm{O}_{\mathrm{k}}$ states conductance of $\mathrm{k}^{\text {th }}$ line related between $\mathrm{i}$ and $\mathrm{j}$ buses. Buses are shown by $\delta_{\mathrm{i}}$ and $\delta_{\mathrm{j}}$ voltage angle of $i$ and j. In Eq. (2) [33], UPQC ${ }_{\text {Cost }}$ is demonstrated. Moreover, R indicates the benefit rate of return, $\mathrm{UPQC}_{\text {Cost }}$ states investment cost, O indicates the UPQC's performance restrictions in MVAr, $\mathrm{UPQC}_{\text {Costyear }}$ indicates the UPQC annual cost, mUPQC indicates the durability of UPQC's. In eq. (3) the VSI idea is shown, where, the voltage magnitude for $\mathrm{b}^{\text {th }}$ bus and $\mu$ indicates small constant. The VSI must be in the limits of 0.9 to 1.1 , and the penalty is supplementary added up, if there is any divergence within this range,

$$
\begin{aligned}
& \mathrm{OB}=\min \left(\mathrm{UPQC} \operatorname{cost}+\mathrm{P}_{\text {Loss }}+\text { VoltageStabilityIndex }\right) \\
& \mathrm{UPQC}_{\text {Cost }}(\mathrm{US}(\$ / \mathrm{kVAr}))=0.0003 \mathrm{O}^{2}-0.2691 \mathrm{O}+188.22 \\
& \mathrm{UPQC}_{\text {Costyear }}=\mathrm{UPQC}_{\text {Cost }} \frac{(1-\mathrm{R})^{\mathrm{mUPQ}} \times \mathrm{R}}{(1+\mathrm{R})^{\mathrm{mUPQC}}-1} \\
& \text { VSI }=\left\{\begin{array}{ll}
1 & \text { if } \quad \mathrm{V}^{\min } \leq \mathrm{V}^{\mathrm{b}} \leq \mathrm{V}^{\max } \\
\exp \left(\mu\left|1-\mathrm{V}^{\mathrm{b}}\right|\right) & \text { otherwise }
\end{array}\right\} \\
& \mathrm{P}_{\text {Loss }}=\sum_{\mathrm{k}=1}^{\mathrm{N}_{\mathrm{L}}} \mathrm{P}_{\text {Lossk }}=\sum_{\mathrm{k}=1}^{\mathrm{N}_{\mathrm{L}}} \mathrm{O}_{\mathrm{k}}\left\{\mathrm{V}_{\mathrm{i}}^{2}+\mathrm{V}_{\mathrm{j}}^{2}-2 \mathrm{~V}_{\mathrm{i}} \mathrm{V}_{\mathrm{j}} \cos \left(\delta_{\mathrm{i}}-\delta_{\mathrm{j}}\right)\right\}
\end{aligned}
$$

Equality and Inequality parameters need to be fulfilled with the proposed model, and it is stated in the following subdivision.

\subsection{Equality Constraints}

The reactive and active line power is to deal with concerning the bus voltage magnitude and phase angle. As a result, the active power balance in DS is shown in eq. (5), and reactive power balance is shown in eq. (6).

$$
\begin{aligned}
& \mathrm{P}_{\mathrm{H}_{\mathrm{i}}}-\mathrm{P}_{\mathrm{E}_{\mathrm{i}}}-\sum_{\mathrm{k}=1}^{\mathrm{N}_{\mathrm{L}}} \mathrm{o}_{\mathrm{ik}}\left\{\mathrm{V}_{\mathrm{i}}^{2}+\mathrm{V}_{\mathrm{j}}^{2}-2 \mathrm{~V}_{\mathrm{i}} \mathrm{V}_{\mathrm{j}} \cos \left(\delta_{\mathrm{i}}-\delta_{\mathrm{j}}\right)\right\}=0 \\
& \mathrm{QU}_{\mathrm{H}_{\mathrm{i}}}-\mathrm{QU}_{\mathrm{E}_{\mathrm{i}}}-\sum_{\mathrm{k}=1}^{\mathrm{N}_{\mathrm{L}}} \mathrm{p}_{\mathrm{ik}}\left\{\mathrm{V}_{\mathrm{i}}^{2}+\mathrm{V}_{\mathrm{j}}^{2}-2 \mathrm{~V}_{\mathrm{i}} \mathrm{V}_{\mathrm{j}} \sin \left(\delta_{\mathrm{i}}-\delta_{\mathrm{j}}\right)\right\}=0
\end{aligned}
$$

In eq. (5), $\mathrm{P}_{\mathrm{H}_{\mathrm{i}}}$ and $\mathrm{P}_{\mathrm{E}_{\mathrm{i}}}$ indicates active power which injects at system active power demand and $\mathrm{i}^{\text {th }}$ bus respectively. $\mathrm{QU}_{\mathrm{H}_{\mathrm{i}}}$ states the reactive power, which was injected at $\mathrm{i}^{\text {th }}$ bus and $\mathrm{P}_{\mathrm{Loss}}$ states the total active power loss. $\mathrm{Q}_{\text {Loss }}$ states the reactive power loss and $\mathrm{QU}_{\mathrm{E}_{\mathrm{i}}}$ states reactive power system demand. $\mathrm{o}_{\mathrm{i}-\mathrm{j}}$ and $\mathrm{p}_{\mathrm{i}-\mathrm{j}}$, states conductance and susceptance, correspondingly which are connected among $\mathrm{i}$ and $\mathrm{j} . \mathrm{V}_{\mathrm{j}}$ and $\mathrm{V}_{\mathrm{i}}$ states voltage magnitude in cooperation of $j$ and $i$ buses. 


\subsection{Inequality Constraints}

These parameters express the system capacity and its functioning limits.

Line flow limit: This limit states maximum power transmission during the meticulous transmission line under the specified circumstance. The limits are dependent on stability or thermal deliberation. In Eq. (7) the power flow limit factor is shown whereas $\mathrm{SE}_{\mathrm{k}}$ max states the maximum value of power flow by means of $\mathrm{k}^{\text {th }}$ line.

$$
\mathrm{SE}_{\mathrm{k}} \leq \mathrm{SE}_{\mathrm{k}} \max
$$

Bus voltage limit: The consideration of bus voltage limit is regarding voltage unbalance limit and voltage magnitude limit node, equivalently. The 3 phase node parameter of the voltage magnitude limit is shown in Eq. (8).

$$
\mathrm{V}^{\min }<\mathrm{V}<\mathrm{V}^{\max }
$$

\section{Mathematical Model of UPQC}

The diagrammatic model of UPQC that is modeled based on a 3-phase 4-wire voltage source converter is demonstrated in Fig 1.

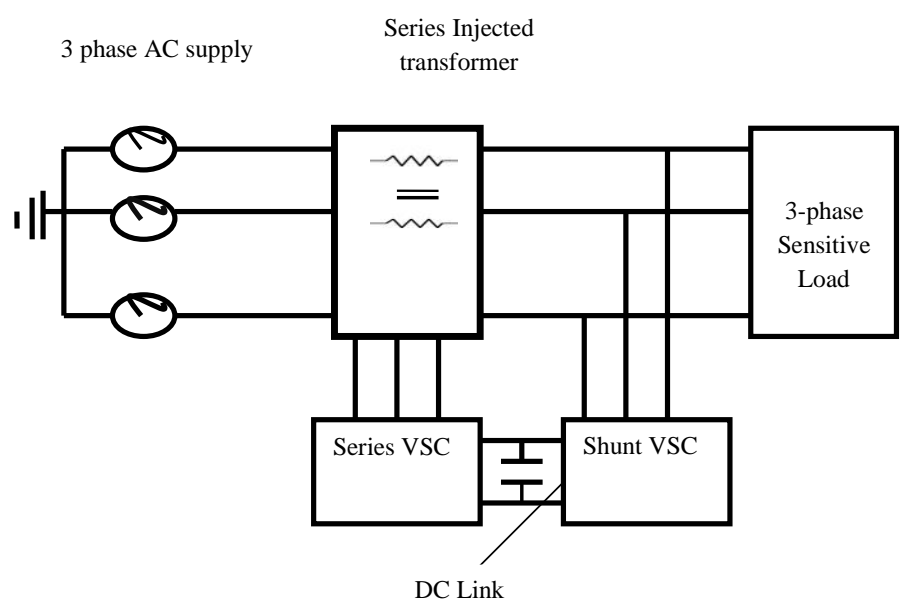

Fig. 1. Schematic illustration of UPQC

In fact, UPQC is designed with series and shunt APF. Usually, shunt Active Power Filter is linked overloads for the reason of recompense complete current associated unease like reactive power compensation; load unbalances compensation, the recompense of current harmonic and regulation of dclink voltage, power factor expansion.

The series APFs are linked using a line by a three-phase series transformer in series. This performs as a controlled voltage source that might recompense and a control voltage source for complete voltage associated unease like, voltage harmonics, and flicker, so on.

UPQC minimizes load disturbance area to a normal functioning zone using the safety of fault. Subsequently, it eases the voltage sag and unbalances, and minimizes loss of real power. 2 inverters that are linked using a single dc storage capacitor is used. Moreover, 1- inverter is installed for series voltage enclosure, and the following one is used for shunt current inclusion. The performance analysis of series inverter, and shunt inverter, follows: injected voltage magnitude via series inverter $\mathrm{V}_{\text {se }}$ chiefly is based on the maximum voltage sag that needs to be enhanced. The source voltage magnitude in normal conditions and voltage sag is represented as $\mathrm{V}_{\mathrm{s}}=\mathrm{kV}_{\mathrm{SO}}$ and $\mathrm{V}_{\mathrm{s}}=\mathrm{V}_{\mathrm{SO}}$ and here $\mathrm{k}_{\mathrm{sag}}=(1-\mathrm{k})$. On some state load voltage, $\mathrm{V}_{\mathrm{L}}=\mathrm{V}_{\mathrm{SO}}=\mathrm{V}_{\mathrm{s}}$. The essential series voltage insertion for mitigating $\mathrm{k}_{\text {sag }}$ p.u of voltage sag is shown in eq. (9). Using UPQC lossless, active power needed via load is shown as active power engaged from the source. In sense, $\mathrm{kV}_{\mathrm{s}} \mathrm{I}_{\mathrm{s}}=\mathrm{V}_{\mathrm{L}} \mathrm{I}_{\mathrm{L}} \cos \phi$ that proffers the source current as stated in eq. (10), whereas $I_{L}$ and $I_{s}$ states the compensated source-end current and the load current. VA series inverter rating is stated as eq. (11) from both eq. (9) and (10), 
Hybrid GWO and CS Algorithm for UPQC Positioning in the Power Distribution Network

$$
\begin{aligned}
\mathrm{V}_{\mathrm{se}} & =\sqrt{\mathrm{V}_{\mathrm{L}}^{2}+\left(\mathrm{kV}_{\mathrm{SO}}\right)^{2}-2 \mathrm{~V}_{\mathrm{L}}\left(\mathrm{kV}_{\mathrm{SO}}\right) \cos \delta} \\
& =\mathrm{V}_{\mathrm{s}} \sqrt{1+\mathrm{k}^{2}-2 \mathrm{k} \cos \delta} \\
\mathrm{I}_{\mathrm{S}}= & \mathrm{I}_{\mathrm{L}} \cos \phi / \mathrm{k} \\
\mathrm{SE}_{\mathrm{se}} & =\mathrm{V}_{\mathrm{se}} \mathrm{I}_{\mathrm{s}}=\mathrm{V}_{\mathrm{s}} \mathrm{I}_{\mathrm{L}} \cos \phi \sqrt{1+\mathrm{k}^{2}-2 \mathrm{k} \cos \delta / \mathrm{k}}
\end{aligned}
$$

Eq. (12) and (13) states active and reactive power distributed with a series inverter, correspondingly, whereas, $\theta_{\mathrm{se}}=180^{\circ}-\tan ^{-1}(\sin \delta / 1-\cos \delta)[12]$.

$$
\begin{aligned}
& \mathrm{P}_{\mathrm{se}}=\mathrm{SE}_{\mathrm{se}} \cos \theta_{\mathrm{se}} \\
& \mathrm{QU}_{\mathrm{se}}=\mathrm{SE}_{\mathrm{se}} \sin \theta_{\mathrm{se}}
\end{aligned}
$$

As stated in Eq. (14), the phrase of recompense current via shunt inverter, $\mathrm{I}_{\mathrm{sh}}$ is stated.

$$
\begin{aligned}
\mathrm{I}_{\mathrm{sh}} & =\sqrt{\mathrm{I}_{\mathrm{s}}^{2}+\mathrm{I}_{\mathrm{L}}^{2}-2 \mathrm{I}_{\mathrm{s}} \mathrm{I}_{\mathrm{L}} \cos (\phi-\delta)} \\
& =\mathrm{I}_{\mathrm{L}} \sqrt{1+\cos ^{2} \phi / \mathrm{k}^{2}-2 \cos \phi \cos (\phi-\delta) / \mathrm{k}}
\end{aligned}
$$

Moreover, as stated in Eq. (15) and (16), shunt inverter regulates harmonic present in load end, whereas $\mathrm{I}_{\mathrm{sh}}^{\mathrm{fu}}$ states fundamental element, $\mathrm{I}_{\mathrm{L}}^{\mathrm{fu}}$ states basic element, $\mathrm{I}_{\mathrm{L}}^{\mathrm{di}}$ states distortion element, $\mathrm{THD}_{\mathrm{L}}$ states the load current THD, THD $\mathrm{Th}_{\mathrm{sh}}$ states the shunt inverter current's Total Harmonic Distribution. Hence, shunt recompense current's Root Mean Square value is shown in eq. (17).

$$
\begin{aligned}
& \mathrm{I}_{\mathrm{L}}^{\mathrm{di}}=\mathrm{I}_{\mathrm{sh}}^{\mathrm{di}} \\
& \mathrm{THD}_{\mathrm{L}} \mathrm{I}_{\mathrm{L}}^{\mathrm{fu}}=\mathrm{THD}_{\mathrm{sh}} \mathrm{I}_{\mathrm{sh}}^{\mathrm{fu}} \\
& \mathrm{I}_{\mathrm{sh}}=\mathrm{I}_{\mathrm{sh}}^{\mathrm{fu}} \sqrt{1+\mathrm{THD}_{\mathrm{sh}}^{2}} \\
& \quad=\mathrm{I}_{\mathrm{L}}^{\mathrm{fu}} \sqrt{1+\cos ^{2} \phi / \mathrm{k}^{2}-2 \cos \phi \cos (\phi-\delta) / \mathrm{k}+\mathrm{THD}_{\mathrm{L}}^{2}}
\end{aligned}
$$

For that reason, the explanation of the shunt inverter's VA rating is stated in eq. (18).

$$
\begin{aligned}
\mathrm{SE}_{\mathrm{sh}} & =\mathrm{V}_{\mathrm{s}} \mathrm{I}_{\mathrm{sh}} \\
& =\mathrm{V}_{\mathrm{S}} \mathrm{I}_{\mathrm{L}}^{\mathrm{fu}} \sqrt{1+\cos ^{2} \phi / \mathrm{k}^{2}-2 \cos \phi \cos (\phi-\delta) / \mathrm{k}+\mathrm{THD}_{\mathrm{L}}^{2}}
\end{aligned}
$$

The reactive and active powers, that are diffused using shunt inverter is demonstrated in Eq. (19) and (20). $\theta_{\mathrm{sh}}=\tan ^{-1}\{\cos (\phi-\delta)-\cos \phi / \sin (\phi-\delta)\}+90^{\circ}-\delta$. The total reactive power which is transported using UPQC is stated in eq. (21) [12].

$$
\begin{aligned}
& \mathrm{P}_{\mathrm{sh}}=\mathrm{SE}_{\mathrm{sh}} \cos \theta_{\mathrm{sh}} \\
& \mathrm{QU}_{\mathrm{sh}}=\mathrm{SE}_{\mathrm{sh}} \sin \theta_{\mathrm{sh}} \\
& \mathrm{QU}_{\mathrm{UPQC}}=\mathrm{QU}_{\mathrm{se}}+\mathrm{QU}_{\mathrm{sh}}
\end{aligned}
$$

\section{Proposed Technique for Optimal Sizing and Positioning of UPQC}

\subsection{Conventional GWO}

GWO [13] is a meta-heuristic technique, imitates wolves' hunting behavior. In GWO, the optimal individual is named $\alpha$ wolf, second- and third-best individuals represented as $\beta$ and $\delta$ wolves, correspondingly, and the other individuals, are named $\omega$ wolves. The wolf behavior of swarm encircling prey is shown in eq. (22).

$$
\mathrm{Y}(\mathrm{t}+1)=\mathrm{Y}_{\mathrm{p}}(\mathrm{t})-\mathrm{B} \cdot\left|\mathrm{D} \cdot \mathrm{Y}_{\mathrm{p}}(\mathrm{t})-\mathrm{Y}(\mathrm{t})\right|
$$

In eq. (22), $\mathrm{Y}$ represents location vector of the wolf, $\mathrm{Y}_{\mathrm{p}}$ indicates the position vector of prey $t$ indicates the number of iterations,

$$
\mathrm{B}=2 \cdot \mathrm{a} \times \mathrm{r}_{1}-\mathrm{a}
$$

$\mathrm{D}=2 \times \mathrm{r}_{2}$ are coefficient, $\mathrm{r}_{1} \in[0,1]$ and $\left.\mathrm{r}_{2} \in[0,1]\right]$ are arbitrary number, and a is computed in eq. (24).

$$
\mathrm{a}(\mathrm{t})=2-\frac{2 \mathrm{t}}{\max _{\mathrm{itr}}}
$$

In eq. (24), $\max _{\text {itr }}$ indicates the utmost number of iterations.

In population, the locations of other individuals are updated using $\alpha, \beta$ and $\delta$ wolves as below.

$$
\begin{aligned}
& Y_{1}=Y_{\alpha}-B_{1} \cdot\left|D_{1} \cdot Y_{\alpha}-Y\right| \\
& Y_{2}=Y_{\beta}-B_{2} \cdot\left|D_{2} \cdot Y_{\beta}-Y\right|
\end{aligned}
$$


Hybrid GWO and CS Algorithm for UPQC Positioning in the Power Distribution Network

$$
\begin{aligned}
& Y_{3}=Y_{\delta}-B_{3} \cdot\left|D_{3} \cdot Y_{\delta}-Y\right| \\
& Y(t+1)=\frac{Y_{1}(t)+Y_{2}(t)+Y_{3}(t)}{3}
\end{aligned}
$$

In eq. (25), (26) and (27), $\mathrm{B}_{1}, \mathrm{~B}_{2}$, and $\mathrm{B}_{3}$ are same as $\mathrm{B}, \mathrm{D}_{1}, \mathrm{D}_{2}$, and $\mathrm{D}_{3}$ are same as $\mathrm{D}$.

\subsection{Conventional CS}

CS [18] is a comprehensively employed meta-heuristics technique, emulates breeding parasitism cuckoos behavior. A solution communicates to a cuckoo egg in CS. Throughout the iterative procedure, the novel candidate solution is formed employing Lévy flight in eq. (29).

$$
\mathrm{Y}_{\mathrm{i}}=\mathrm{Y}_{\mathrm{i}}-\gamma \cdot\left|\mathrm{Y}_{\mathrm{i}}-\mathrm{Y}_{\mathrm{g}}\right| \oplus \operatorname{levy}(\lambda)=\mathrm{Y}_{\mathrm{i}}+\frac{0.01 \mu}{|\mathrm{v}|^{1 / \lambda}}\left(\mathrm{Y}_{\mathrm{i}}-\mathrm{Y}_{\mathrm{g}}\right)
$$

In eq. (29), $\lambda$ indicates the Lévy flight exponent, $\mathrm{Y}_{\mathrm{i}}$ indicates the $\mathrm{i}^{\text {th }}$ solution, $\oplus$ denotes entry-wise multiplications, $\mathrm{Y}_{\mathrm{g}}$ indicates global optimal solution, $\gamma>0$ indicates step scaling size, $\mathrm{u}$ and $\mathrm{v}$ denotes arbitrary numbers, and they, are satisfied by means of normal distribution [14]:

$$
\begin{aligned}
& \mathrm{uN}\left(0, \sigma_{\mathrm{u}}^{2}\right), \mathrm{vN}\left(0, \sigma_{\mathrm{v}}^{2}\right) \\
& \sigma_{\mathrm{u}}=\left[\frac{\sin \left(\frac{\lambda \pi}{2}\right) \cdot \Gamma(1+\lambda)}{2^{(\lambda-1) / 2} \lambda \cdot \Gamma\left(\frac{1+\lambda}{2}\right)}\right]
\end{aligned}
$$

In eq. (31), $\Gamma($.$) denotes Gamma function.$

In addition, CS exploits detection operator to put back finds out nests through probability $p_{a}$ in eq. (32) [14]:

$$
Y_{i}= \begin{cases}Y_{i}+r n \cdot\left(Y_{j}-Y_{k}\right), & \text { if } p>p_{a} \\ Y_{i}, & \text { else }\end{cases}
$$

In eq. (32), $\mathrm{p} \in[0,1]$ denotes a random number $\mathrm{Y}_{\mathrm{j}}$ and $\mathrm{Y}_{\mathrm{k}}$ indicates the candidate solutions from the population, correspondingly.

\subsection{Opposition Learning Scheme}

The GWO algorithm was effectively used for technical and a lot of engineering fields [17]. Nevertheless, about [15], the conventional GWO approach is superior at local exploitation, however, reduced at global exploration. Hence, one vigorous research subject is to improve the global exploration capability of Grey Wolf Optimization. OBL [21] is a competently exploration-improved method which was comprehensively exploited meta-heuristic techniques to make stronger their global exploration capacity. The Opposition based Learning method is stated as follows:

Description 1: Opposite number. Consider y as a real number, its opposite number $\mathrm{y}^{\prime}$ is stated in eq. (33)[16]:

$$
\mathrm{y}^{\prime}=1+\mathrm{u}-\mathrm{y}
$$

In eq. (33), 1 and $\mathrm{u}$ denotes lower and the upper boundary of $\mathrm{y}$.

Description 2: Opposite solution. Eq. (34) has the ability to comprehensive D-dimensional search space. Presumptuous that $\mathrm{Y}=\left(\mathrm{y}_{1}, \mathrm{y}_{2}, \ldots . ., \mathrm{y}_{\mathrm{D}}\right)$ is a solution in $\mathrm{D}$-dimensional search space. The opposite solution of $\mathrm{Y}$ is stated in $\mathrm{Y}=\left(\mathrm{y}_{1}^{\prime}, \mathrm{y}_{2}^{\prime}, \ldots . ., \mathrm{y}_{\mathrm{D}}^{\prime}\right)[16]$ :

$$
\mathrm{y}_{\mathrm{i}}^{\prime}=\mathrm{l}_{\mathrm{i}}+\mathrm{u}_{\mathrm{i}}-\mathrm{y}_{\mathrm{i}}, \quad \mathrm{i}=1,2, \ldots . . \mathrm{D}
$$

In conclusion, the values of fitness function are $\mathrm{f}(\mathrm{Y})$ and $\mathrm{f}\left(\mathrm{Y}^{\prime}\right)$ are calculated.

If $\mathrm{f}(\mathrm{Y})$ is better $\mathrm{f}\left(\mathrm{Y}^{\prime}\right)$, $\mathrm{Y}$ is elected; if not, $\mathrm{Y}^{\prime}$ is elected.

In recent times, the Opposition Based Learning approach is employed to Grey Wolf Optimization technique to progress its performance [17]. Dissimilar from [17], this paper employs OBL mode to make decision layer individuals ( $\alpha, \beta$ and $\delta$ wolves) utilizing probability $\mathrm{p}_{\mathrm{b}}$ to additional enhance population diversity. Fig 2 indicates the flow chart of the proposed model. 


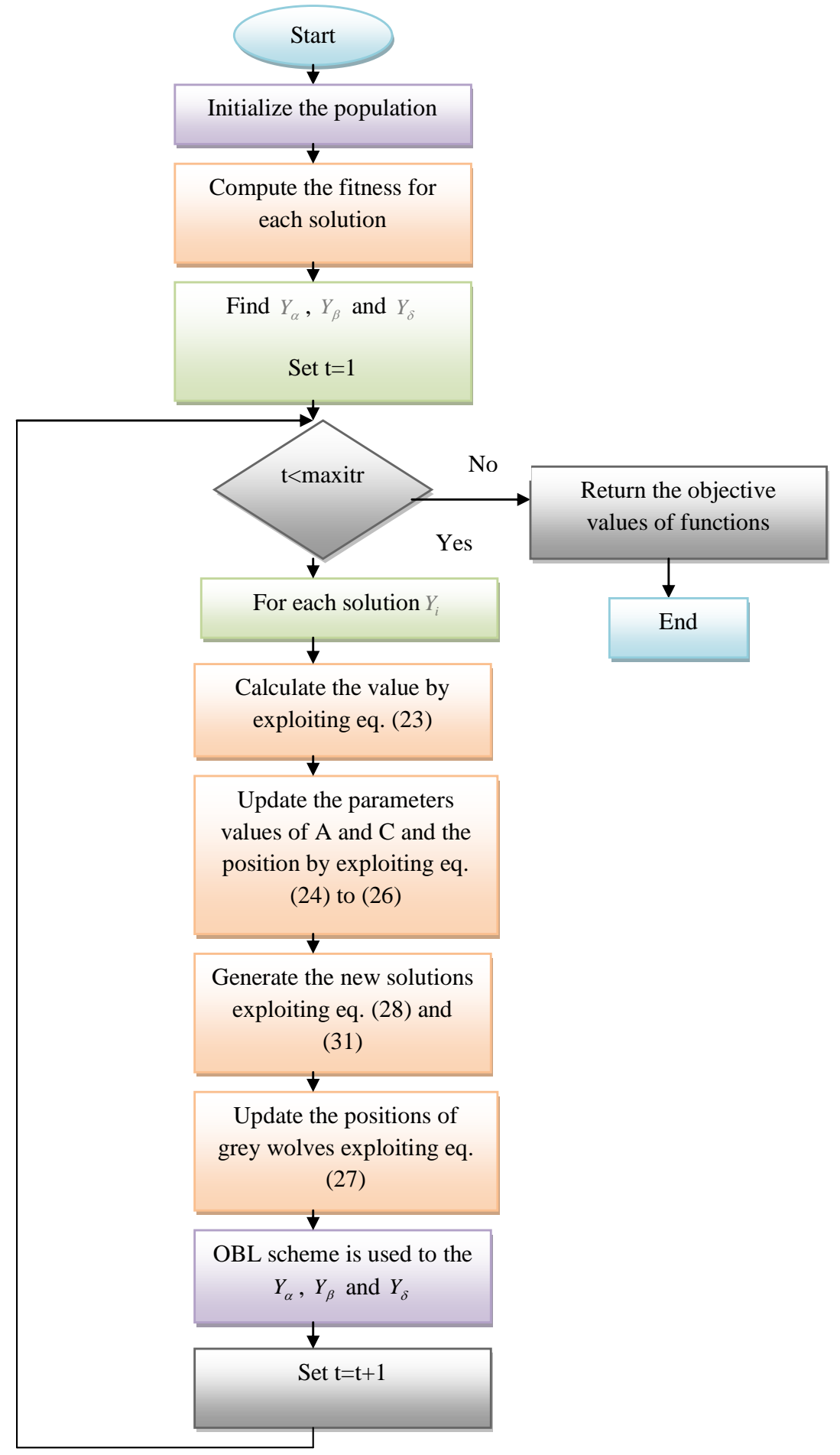

Fig. 2. Fow chart of the developed model

\section{Results and Discussions}

\subsection{Experimental Procedure}

The developed model was implemented in MATLAB 2017. Moreover, 2 diverse bus systems were used namely IEEE 33 and the IEEE 69 bus system. Three analyses were performed based upon the position of UPQC such as one location, two locations, and three locations. The evaluation was done with existing models such as GWO, WOA, FF, ABC, WS-WU, DA, and GA for both bus systems and consequences were accomplished. 


\subsection{Performance Analysis}

Tables 1 and 2 summarize the performance analysis of developed technique over traditional techniques for IEEE 33 and the IEEE 69 bus system in the various numeral of location (1, 2, and 3). Here, in Table 1 and 2 accurate value shows that the proposed method attains minimized fitness value while illustrious to former techniques. Meanwhile, the performance analysis regarding the fitness evaluation is stated in Tables 1 and 2 for the three locations.

Table 1: Analysis of the developed and existing techniques in IEEE 33bus system

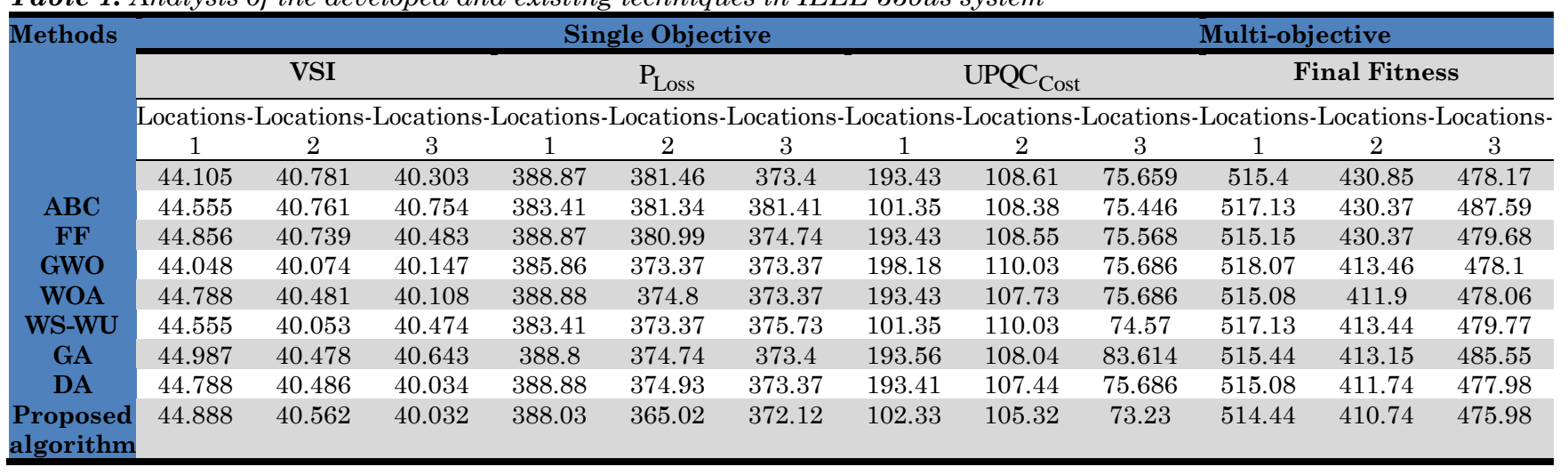

Table 2: Analysis of the developed and existing techniques in IEEE 69 bus system

\begin{tabular}{|c|c|c|c|c|c|c|c|c|c|c|c|c|}
\hline \multirow{4}{*}{ Methods } & \multicolumn{9}{|c|}{ Single objective } & \multirow{2}{*}{\multicolumn{3}{|c|}{$\begin{array}{c}\text { Multi-objective } \\
\text { Final Fitness (OB) }\end{array}$}} \\
\hline & \multicolumn{3}{|c|}{ VSI } & \multicolumn{3}{|c|}{$\mathrm{P}_{\text {Loss }}$} & \multicolumn{3}{|c|}{$\mathrm{UPQC}_{\text {Cost }}$} & & & \\
\hline & Loca & ocation & awe & . & ocation & & catio & Locations- & atis & ocation & ocatior & ocations \\
\hline & 1 & 2 & 3 & 1 & 2 & 3 & 1 & 2 & 3 & 1 & 2 & 3 \\
\hline $\mathrm{ABC}$ & 33.318 & 31.966 & 31.966 & 316.89 & 303.8 & 303.81 & 305 & 108.83 & 85.853 & 553.31 & 533.39 & 500.53 \\
\hline FF & 33.308 & 33.308 & 31.968 & 316.53 & 316.51 & 303.6 & 199.18 & 105.83 & 85.866 & 538.99 & 553.55 & 500.33 \\
\hline GWO & 33.318 & 31.968 & 31.958 & 316.89 & 303.89 & 303.35 & 305 & 108.55 & 85.835 & 553.31 & 533.3 & 500.03 \\
\hline WOA & 33.318 & 33.318 & 33.013 & 316.89 & 316.89 & 305.55 & 305 & 106.86 & 85.895 & 553.31 & 556.08 & 503.35 \\
\hline WS-WU & 33.336 & 31.988 & 19.193 & 330.96 & 303.3 & 300.61 & 183.36 & 106.86 & 85.851 & 536.65 & 533.15 & 395.65 \\
\hline GA & 33.331 & 33.063 & 31.968 & 330.96 & 306.58 & 303.89 & 183.36 & 105.33 & 85.689 & 536.65 & 533.96 & 500.55 \\
\hline DA & 33.336 & 31.968 & 31.968 & 330.96 & 303.89 & 303.89 & 183.36 & 108.55 & 85.686 & 536.65 & 533.3 & 500.55 \\
\hline $\begin{array}{l}\text { Proposed } \\
\text { algorithm }\end{array}$ & 33.336 & 19.368 & 19.193 & 330.96 & 303.65 & 300.61 & 183.36 & 108.5 & 85.851 & 536.65 & 530.31 & 395.65 \\
\hline
\end{tabular}

\section{Conclusion}

The most important aspire of this article is to present an enhancement of the PQ model which was based on hybrid, GWO, and CSA for optimal sizing and the location of UPQC in power DS. The best solution was designed based upon the opposition based learning model of GWO in CS and hence, the developed technique was called Hybrid GWO -CS. In addition, the developed Hybrid GWO -CS algorithm discovers the optimal position of the UPQC device by taking into consideration of the power losses, UPQC cost, and VSI. In addition, the developed technique performance was analyzed in IEEE 33and 69, bus systems, and they were differentiated over other conventional techniques such as FF, ABC, WOA, GWO, GA WS-WU, and DA and the outcomes were obtained. Thus, the performance of the developed model was verified resourcefully by experimentation analysis. To optimize performance and power systems stability and to conquer PQ issues, optimal sizing and the position of UPQC in power system was deployed exploiting the developed method.

\section{References}

[1] Ashish Patel, Sisir K. Yadav, Hitesh D. Mathur, Surekha Bhanot, Ramesh C. Bansal,"Optimum sizing of PV based UPQC-DG with improved power angle control", Electric Power Systems ResearchVolume 182May 2020.

[2] Guilherme Masquetti Pelz, Sergio Augusto Oliveira da Silva, Leonardo Poltronieri Sampaio,"Distributed generation integrating a photovoltaic-based system with a single- to three-phase UPQC applied to rural or remote areas supplied by single-phase electrical power", International Journal of Electrical Power \& Energy Systems, Volume 117,May 2020.

[3] S. Lakshmi Kanthan Bharathi, S. Selvaperumal," MGWO-PI controller for enhanced power flow compensation using unified power quality conditioner in wind turbine squirrel cage induction generator" Microprocessors and Microsystems, Volume 76, July 2020. 
[4] Ashish Patel, H. D. Mathur, Surekha Bhanot,"An improved control method for unified power quality conditioner with unbalanced load", International Journal of Electrical Power \& Energy SystemsVolume 100,September 2018, Pages 129-138.

[5] Brahim Berbaoui," Fuzzy multi-objective technique combined with VCS algorithm for unified power quality conditioner based on hybrid power source PEMFC/SC", International Journal of Hydrogen EnergyVolume 43, Issue 1222, Pages 6275-6293, March 2018.

[6] N. Gowtham, Shobha Shankar,"UPQC: A Custom Power Device for Power Quality Improvement", Materials Today: Proceedings, Volume 5, Issue 1, Part 1Pages 965-972.

[7] Ghosh A, Ledwich G. A unified power quality conditioner (UPQC) for simultaneous voltage and current compensation. Electr Power Syst Res vol. 59, no.(1):55e63, 2001.

[8] Tejasvi R, Kumar DG, Bhoopal N. An improved grid-voltage regulation by using fuel cell based iUPQC controller. Int J Adv Eng Global Technol 5(4):1843e8, July 2017.

[9] sumathi anjana rani Ch, swapna Simhadri, srinu k. Mitigation of voltage sag and current harmonics using UPQC base PEMFC. IRJET 2016;3(11):1369e73.

[10] Brahim B, Chellali B, Rachid D, Brahim F. Optimization of shunt active power filter system fuzzy logic controller based on ant colony algorithm. J Theor Appl Inf Technol 2010;14:117e25.

[11] Kanjiya P, Singh B, Chandra A, Al-Haddad K. "SRF Theory Revisited' to control self-supported dynamic voltage restorer (DVR) for unbalanced and nonlinear loads. IEEE Trans Ind Appl 2013;49(5):2330e40.

[12] Jayanti Sarker and S.K. Goswami, "Optimal Location of Unified Power Quality Conditioner in Distribution System for Power Quality Improvement", Electrical Power and Energy Systems, volume. 83, page no. 309-324, 2016.

[13] Mirjalili S, Mirjalili SM, Lewis A. Grey wolf optimizer. Adv Eng Softw;vol.69, page no. 46-61, 2014.

[14] Yang X, Deb S. Cuckoo search via levy flights. World congress on nature \& biologically inspired computing. IEEE; 2009. p. 210-4.

[15] Gupta S, Deep K. A novel random walk grey wolf optimizer. Swarm Evol Comput, vol.44, page no 101-12, 2019.

[16] Tizhoosh HR. Opposition-based learning: a new scheme for machine intelligence. Int Conf Comput Intell Model Control Auto;1, page no 695-701, 2005.

[17] Ibrahim RA, Elaziz MA, Lu S. Chaotic opposition-based grey wolf optimization algorithm based on differential evolution and disruption operator for global optimization. Expert Syst Appl;vol. 108, page no 1-27, 2018.

[18] T.C.Subramanyam,S S Tulasi Ram and J B V Subrahmanyam,"HGAGWO: A Multi-Objective Optimal Positioning and Sizing of Fuel Cells in DG Systems",Journal of Computational Mechanics, Power System and Control (JCMPS), Volume 1, Issue 1, October 2018.

[19] Shilpa S. Shrawane Kapse,Dr. Manoj B. Daigavane and Dr. Prema M. Daigavane," Localization and Sizing of UPFC: A Hybrid Optimization Algorithm for Solving Reactive Power Dispatch",Journal of Computational Mechanics, Power System and Control (JCMPS),Volume 2, Issue 1, January 2019.

[20] Kaladhar Gaddala,Sangameswara Raju P,"Enhanced Self Adaptive Bat Algorithm for Optimal Location of Unified Power Quality Conditioner",Journal of Computational Mechanics, Power System and Control (JCMPS),Volume 2, Issue 3, July 2019. 